\title{
EXPRESSÕES DO CIBERFEMINISMO NA CONTEMPORANEIDADE
}

\author{
Cyberfeminism's expressions in the \\ contemporaneity
}

Cristina Tavares da Costa Rocha*

The central point remains: there is a credibility gap between the promises of Virtual Reality and cyberspace and the quality of what it delivers. It consequently seems to me that, in the short range, this new technological frontier will intensify the gender-gap and increase the polarisation between the sexes. We are back to the war metaphor, but its location is the real world, not the hyperspace of abstract masculinity. And its protagonists are no computer images, but the real social agents of post industrial urban landscapes. The most effective strategy remains for women to use technology in order to disengage our collective imagination from the phallus and its accessory values: money, exclusion and domination, nationalism, iconic femininity and systematic violence (BRAIDOTTI, Rosi, 2006).

\section{Resumo}

O objetivo deste texto é contribuir com informações e reflexões para o campo de estudos de gênero e tecnociência no que diz respeito a um dos seus mais recentes segmentos: o ciberfeminismo. Explicito algumas de suas expressões nos trabalhos desenvolvidos por mulheres na área das ciências

* Mestre em Tecnologia pelo Programa de Pós Graduação em Tecnologia (PPGTE) da Universidade Tecnológica Federal do Paraná (UTFPR) e doutora em Ciências Humanas pela Universidade Federal de Santa Catarina (UFSC). Pesquisadora Colaboradora no Instituto de Estudos de Gênero (IEG/UFSC) e Integrante do Grupo de Estudos e Pesquisas em Relações de Gênero e Tecnologia do PPGTE (GeTec/UTFPR).

(cristinarocha@cfh.ufsc.br) 
exatas, que é um reduto hegemônica e historicamente masculino. Essa explicitação é evidenciada nas narrativas das entrevistadas enquanto recorte dos resultados de investigação realizada em laboratórios de informática/ computação de universidades públicas e de instituições de pesquisa no sul e sudeste do país.

Palavras-chave: Gênero; tecnociência; ciberfeminismo.

\section{Abstract}

This text aims to contribute with informations and reflections to gender and technoscience study field towards one of its most recent segments: cyberfeminism. I explicit some of its expressions in the works developed by women in the exact sciences area, which is hegemonic and historically male context. This explicitness is evidenced in the interviewed's narratives taking off from the results of an investigation made in informatics and computational laboratories of public universities and research institutes in the South and Southeast of the country.

Keywords: Gender; technoscience; cyberfeminism.

Este texto apresenta reflexões preliminares sobre pesquisa ${ }^{1}$ a respeito de contextos aqui denominados laboratoriais, que são representativos das expressões do ciberfeminismo na contemporaneidade. Não obstante esses contextos sejam tidos até então como hegemonicamente masculinos, as mulheres têm aí adentrado cada vez mais, principalmente após o advento da sociedade interligada por redes computacionais de trabalho e de lazer, redes estas propiciadas pelas novas tecnologias da informação e da comunicação (Castells, 1999). O intuito principal deste texto é contribuir com informações e reflexões para a área dos estudos de gênero. Inspiro-me em teóricas do ciberfeminismo, como Donna Haraway, Sadie Plant, Rosi Braidotti, dentre outras; explicito alguns dos contextos por mim visitados, no sul e sudeste do País, a exemplo de laboratórios de informática e computação de universidades

1 Pesquisa iniciada em 2002, ainda em execução. 
públicas e de instituições/fundações de pesquisa que têm parceria com projetos universitários. Opto por abordagem qualitativa de cunho interpretativo. Nesses locais tive oportunidade de fazer observação in loco. Informo sobre profissionais entrevistadas/os na ocasião das visitas, privilegiando o depoimento de mulheres. E, enfim, apresento algumas das considerações finais, que evidenciam certas tendências inovadoras no sentido de uma maior inclusão e penetrabilidade delas nesses contextos e reconhecimento de suas atividades ${ }^{2}$.

\section{CIBERFEMINISMO}

Há mulheres desempenhando funções e atuando de diversos modos nos novos espaços internéticos propiciados pela interconexão em rede de computadores, que tem facilitado a comunicação humana. Esta interconexão resulta em uma "sociedade em redes" e tem caracterizado a atual era, como a da informação e a da comunicação, a facilitar a construção do conhecimento e a colaborar na aquisição do aprendizado. Ao puxar o fio histórico sobre o uso dessas recentes tecnologias pelas mulheres encontro o ciberfeminismo.

Este, enquanto segmento dos estudos de gênero e da tecnociência ${ }^{3}$ atual, tem duas gêneses distintas (Ileana Stofenmacher, 2005). Uma delas, e é a que opto por inspirar o desenvolvimento deste estudo, surge com Sadie Plant (1999). Ela começou a usar o termo ciberfeminismo para identificar toda e qualquer problemática relacionada às mulheres e à tecnologia. Portanto, o movimento ciberfeminista tem, em sua base, a cooperação

2 Há outros textos em construção, evidenciando discriminações e preconceitos denunciadores de posturas androcêntricas ainda vigentes. Um deles foi apresentado no Encontro Internacional Fazendo Gênero VII, ocorrido em Florianópolis-SC, de 28 a 30 de agosto de 2006.

3 Haraway conceitua tecnociência como não distinção entre "ciência e tecnologia tanto quanto entre natureza e sociedade, sujeitos e objetos, natural e artificial que estruturaram o tempo imaginário chamado modernidade" (1997, pág. 3). Para Haraway, as relações sociais, também entendidas nos contextos da contemporaneidade, como alianças sociotécnicas, integram diversidade e multiplicidade de temas da tecnociência no final do século 20. Dentre estes temas, pode-se citar assuntos vinculados a: necessidades militares, processos democráticos, investigações acadêmicas, desenvolvimento do comércio e da economia, acesso ao conhecimento e ao aprendizado, processos de padronização e globalização, além de saúde. No geral, tais alianças sociotécnicas permanecem atravessadas por relações assimétricas e estigmatizadas de gênero, raça e etnia, nas diferentes camadas sociais e geracionais. 
entre mulher, máquina e novas tecnologias, objetivando a liberação da mulher de tradicionais injustiças e assimetrias de valores e poderes em que vivem. Em síntese, o computador seria uma espécie de epicentro de ações visando a mudanças no mundo globalizado, a atividades alternativas através da necessária fusão entre tecnologia e cultura, na tentativa de eliminação de poderes centralizados, hierarquizados e androcêntricos, em favor de comunicações também mais horizontais, possíveis pela liberdade de informação ${ }^{4}$.

A outra gênese iniciou-se na cidade de Adelaide, na Austrália, através da ação conjunta de quatro artistas. Elas criaram um grupo experimental de trabalho - VNS Matrix - que tinha, aprioristicamente, um único objetivo: divertir-se com a arte na intersecção com a teoria feminista de cunho francês, produzindo textos enquanto obras de arte. O primeiro de uma série desses trabalhos foi produzido em homenagem a Haraway e ao seu conceito de ciborgue, exposto no texto intitulado Manifesto para o século XXI. As propostas prioritárias do grupo - e que foram seguidas por outras feministas em diversos países - eram não apenas explorar o ciberespaço como construção de espaço de sociabilidade, de identidades, subjetividades, e sexualidades, mas principalmente pesquisar as narrativas de dominação e controle na ambientação virtual.

O ciberfeminismo, dentro da conceituação proposta por Plant (1999), tem raízes nos primórdios da computação. Apesar da hegemonia masculina nestes redutos de trabalho e lazer, há dados que evidenciam que, em diversos países, mulheres têm estado presentes também nestes cenários digitais-computacionais e têm tido desempenhos considerados por seus pares como brilhantes, principalmente nos países desenvolvidos, como os EUA. Um exemplo é Ada Byron, mais conhecida como Ada Lovelace, filha única do poeta Lord Byron e da matemática Annabella.

4 Alerta-se, porém, que há correntes de pensadoras, a exemplo de Stofenmacher, que entendem o ciberfeminismo como movimento ainda em gestação, dado seu breve tempo em curso, menos de quinze (15) anos e, portanto, não se constituiria em uma teoria já fundamentada, e muito menos em uma corrente ideológica firmada, por insuficiência de bases sólidas. Além disso, na conceituação de Plant, não obstante ela própria seja militante do feminismo, não estaria atrelada a este conceito posicionamento de militância política feminista. Ressalto que nenhuma das minhas entrevistadas tinha qualquer preocupação com este movimento. 
Viveram na Inglaterra, na época vitoriana, no século XIX. Ada trabalhou ativamente com o engenheiro Charles Babbage, em seu invento Engenho Analítico. Lovelace desenvolve a primeira programação de computador ${ }^{5}$ (PLANT, 1999).

Outro exemplo é a ação profissional desenvolvida por uma mulher que atuou na fase inicial dos Sistemas de Informação e de Comunicação, sistemas estes mediados pela tecnologia computacional: Grace Murray Hooper ${ }^{6}$ (1906 - 1992), PhD em Matemática e Física pela Universidade de Yale. Isto porque ela liderou equipes no campo dos conceitos de desenvolvimento de softwares e contribuiu para a transição de técnicas de programação primitivas, até utilização de sofisticados compiladores. Na década de 1940, participou da equipe que trabalhava com os computadores Mark I, II e III. Grace Murray Hooper também colaborou para a concepção e produção do UNIVAC I, o primeiro computador digital eletrônico de grande escala. Foi uma das principais responsáveis pela primeira linguagem de programação feita na década de 1950.

Num dia quente de verão de 1945 , uma queda inexplicável no sistema de computação fez Grace Murray Hopper e sua equipe ficarem confusos e frustrados. Eles estavam construindo o computador Mark II, e uma das metas era calcular o ângulo de inclinação dos novos canhões anti-aéreos da marinha americana. Trabalhavam temporariamente em um prédio sem ar condicionado, estando, por causa do forte calor de verão, com todas as janelas abertas, na tentativa de arejar o quente e úmido ambiente. Não conseguiam entender uma razão aparente para a súbita parada da máquina. Finalmente, abriram-na e perceberam que havia uma mariposa dentro nela, exatamente sobre o circuito condutor. Claro que esta sofreu imediata combustão, o que interrompeu o funcionamento do circuito. Hopper removeu cuidadosamente o referido inseto (bug, em inglês) do Mark II e o colou com fita adesiva no seu livro de registros. E anotou ao lado dela: "primeiro caso real de mariposa encontrada". Grace escreveu que a partir daquele dia ninguém mais iria consertar um computador,

5 Naqueles tempos vigorava o sistema analógico e não digital, como nos dias atuais.

6 Artigo: A incrível Grace: A mãe do Cobol. Disponível em < http://www.interon.com.br > Acesso em 19 ago 2003. Além deste site, há diversos outros que contam a história de Grace Murray Hopper, a exemplo, também, do site disponivel em: < http://www.pbs.org/wgbh/aso/databank/entries/btmurr. html> Acesso em 07 set 2004. 
e sim "debugá-lo". Portanto, foram creditados a ela os termos $b g^{7}$ e debug para significar, respectivamente, quebras de sistemas de computação e como fixá-los. Desta maneira, bug passou a indicar qualquer problema de mal-funcionamento que ocorra com sistemas computacionais, tanto físicos (superaquecimento do processador, incompatibilidade de hardware, etc.) quanto lógicos (aplicativos mal-escritos) ${ }^{8}$.

Outro exemplo é Sarah Flannery. Em 1999, ela tinha 16 anos e recebeu o prêmio "Jovem Cientista do Ano" na Irlanda, pelo seu trabalho sobre criptografia na Internet. Esta é uma área considerada um reduto masculino por excelência, tanto que ela foi descrita em livro como "hacker de 16 anos" (The Hacker Ethic). Com 19 anos, era estudante na Universidade de Cambridge, EUA. Posteriormente, lançou um livro - In Code: A Mathematical Journey, escrito em conjunto com seu pai, contando sobre suas aventuras na área da matemática e da criptografia, incluindo, portanto, o ambiente digital. Ainda um outro ícone feminino neste universo tido como solidamente masculino é Jude Milhon, conceituada programadora de sistemas de informação, citada como uma das primeiras hackers ${ }^{9}$ femininas no livro de Steven Levy, Hackers: Heroes of the Computer Revolution, lançado em 1984 (NYTimes, 2001).

Como estes casos, poderiam ser aqui mencionados diversos outros acontecidos no exterior e também no Brasil ${ }^{10}$, envolvendo mulheres na

7 Na passagem para o ano 2000 ficou famosa a frase "o bug do milênio" para se referir a um erro programação computacional que resultaria em quebra global nos sistemas de informação e comunicação que interconectam as redes entre si e elas com a Internet.

8 Disponível em: <http://planeta.terra.com.br/informatica/dicinfo/atom.htm> Acesso em 08 set 2004.

9 Os artigos, no geral, usam a palavra hacker indistintamente. Hackers não são vistos/as como criminosos/as da computação, embora este seja o termo mais conhecido e mais associado a eles/ as. Trata-se de alguém que adora escrever códigos de programação e se diverte explorando os recantos e as aberturas da rede (Internet e outras redes privadas), visando à captura de vírus, que outros especialistas lançam nessas mesmas redes. Portanto, são entendidos no sentido original da palavra, isto é, entusiastas programadores/as de computação. O/A perigoso/a e mau/má invasor/a de sistemas é conhecido/a como cracker, que lança os famigerados vírus que infectam computadores do mundo todo.

10 No Brasil, uma das mais conceituadas hackers dentre os/as que estão envolvidos/as com a área é Sulamita Garcia, com quem troquei e-mails durante a fase inicial desta pesquisa (Diário de Campo, janeiro de 2003). Em algumas empresas nascentes de base tecnológica pude constatar sua notoriedade e respeitabilidade por parte dos pares, através de falas de homens que entrevistei (Diário de Campo, fevereiro de 2004). 
área da produção dos sistemas de informação, a prestarem importantes colaborações, inclusive algumas premiadas por terem sido excelentes hackers, reduto que se tem como predominantemente masculino.

Plant (1999, pág. 135 e seguintes), em seu livro Mulher Digital, traça parte da trajetória profissional da mulher, focando o campo da tecnologia nos EUA. Informa que, à época tanto da I quanto da II Grande Guerra, as mulheres foram requisitadas para trabalharem com computação, não apenas nas tentativas de encontrar soluções para problemas balísticos, direcionados à elaboração de cálculos "das tabelas de disparo, destinadas a aperfeiçoar a sincronização e trajetória de mísseis, bombas e obuses”, mas também nas atividades de comunicações militares. Os artilheiros habituaram-se a consultar estas tabelas antes de apontarem e dispararem contra seus alvos. Muitas destas mulheres, que executaram estes trabalhos especializados foram, posteriormente, recrutadas com o objetivo de construir máquinas destinadas a executar este mesmo trabalho.

Além disso, havia mulheres trabalhando na construção do programa do Integrador e Computador Numérico Eletrônico (ENIAC), o primeiro computador eletrônico programável, usando sistemas binários de zero e um. Foi lançado em 1946. Havia, também, o "Colossus [que] surgiu do trabalho feito durante a I Grande Guerra, com o Enigma - que cifrava e decifrava mensagens - e das tarefas estreitamente correlatas de quebrar códigos cifrados em outras máquinas alemãs" (PLANT, 1999, pág. 136). Este tipo de trabalho acabou sendo revelado cerca de trinta anos após o término da guerra. A demora na revelação deveu-se ao fato de que esta tarefa era considerada de caráter ultra-secreto. Esta atividade dependeu do trabalho "de quase duas mil mulheres do Corpo Feminino Naval (...), várias estudantes de línguas das forças militares e "moças heróicas escolhidas a dedo, que ingressaram na Marinha (...)"11.

11 No entanto, ressalta-se que há controvérsias quanto às abordagens de Plant, no sentido de que emergiram interpretações contrárias às que ela elabora, denunciando que as mulheres foram subutilizadas de modo geral, nessa época, mal-remuneradas e inclusive ocupando lugares de homens, que ficaram desempregados em massa; e que a autora levanta tais elementos de forma imprecisa e não thes dando a devida relevância, embora esses elementos sejam considerados por correntes feministas como importantes para a análise de toda a situação sócio-cultural da época enfocada em seu livro. 
Ainda, segundo Plant (1999), os microchips e microprocessadores tornam-se cada vez mais onipresentes no dia-a-dia dos indivíduos, tornando os produtos sofisticadamente digitais, visto que são encontrados em prédios, estradas, refrigeradores, rádios, telefones, fax, teclados, seletores; e até mesmo em roupas e nas placas de identificação de animais domésticos.

Hoje em dia, a presença dos microprocessadores se amplia e é real também para a área do entretenimento, visto que, por exemplo, até os jogos computacionais tornam-se corriqueiros principalmente na faixa etária infanto-juvenil, mas também adulta. Nesse campo de atuação, há a artista digital ciberfeminista Anne-Marie Schleiner, designer e curadora da arte hacker, que tem revolucionado os jogos computacionais, com construções consideradas inusitadas, até então, ao criar seu projeto Mutation.Fem. Essa atividade, iniciada por brincadeira decorrente de seu cansaço ao verificar o sexismo machista nos jogos de computador, resulta em trabalho carregado de ideologia feminista. Isto porque, inconformada com ações dos EUA após o "11 de setembro" 12 , e muito mais com a ideologia xenófoba e fascista contida nos jogos de guerra (principalmente o Counter Strike) do que com a violência expressada e incentivada nesses jogos, ela cria um programa tal que permite às/aos jogadoras/es se infiltrarem nos jogos on-line e, ao invés de matar o maior número possível de inimigos, são instadas/os a inserir cartazes virtuais e/ou grafitar frases pacifistas, e a criar avatares ${ }^{13}$ femininos, incentivando a deposição de suas armas. Além disso, esta ciberfeminista cria o jogo Anime Noir, em que os personagens femininos são transgêneros, as/os quais, além de provocar mutação de sexo, ainda podem cruzar espécies. Ela tem como meta "associações estratégicas, contradições irônicas e posições livres de gênero”. E professa a democratização da cultura eletrônica, permitindo aos/às usuários/as que

12 O "11 de setembro" (do ano 2001) refere-se aos ataques terroristas aos EUA por parte de AlQaeda, organização, supostamente sob comando de Osama Bin Laden, como apregoa parte da imprensa, que divulga discurso do alto comando dos EUA. Nesse dia, dois aviões pilotados por membros da organização atingiram o World Trade Center (WTC), conhecido como "as torres gêmeas”, coração financeiro e simbólico de New York/EUA. Outro avião da mesma organização, nas mesmas horas, atingiu parte do Pentágono.

13 Avatares são personagens criados por jogadores/as no ambiente virtual. 
interfiram e modifiquem jogos e softwares. Um de seus projetos prioritários, o Opensorcery, explora e promove sistemas abertos, pois entende que a democratização na elaboração de softwares tem potencial para mudar o mundo, propiciando a diluição dos "limites rígidos de gênero, abrindo espaço para o cyberfeminismo e outras correntes tecno-culturais marginais, podendo mudar também a cyber-economia, transformando o comércio eletrônico numa economia de doações" (LEONEL, 2004).

\section{O CIBERFEMINISMO NOS CONTEXTOS LABORATORIAIS DE INFORMÁTICA/COMPUTAÇÃO NO SUL E SUDESTE DO PAÍS}

A partir da abordagem do ciberfeminismo adotada por Plant (1999), todas as entrevistadas na pesquisa ora em curso estariam a exercê-lo, mesmo que isentas de posturas de militância feminista, visto que suas atividades profissionais estão vinculadas, em graus variados de centralidade ou de periferia, com os espaços e mecanismos da cibercultura ${ }^{14}$. Elas trabalham com produção e desenvolvimento de processos, serviços, soluções e/ou artefatos envolvidos por sistemas e redes de computação, engenharias de softwares e hardwares.

As entrevistadas ${ }^{15}$ apresentam o seguinte perfil: são brancas, faixa etária média de 27 anos, provêm da camada média da população; informam ter mais facilidade com a área das Ciências Exatas, motivo pelo qual graduaramse em cursos de engenharia, informática, ciências da computação e sistemas de informação; além disso, estão integradas em programas de mestrado; a renda delas provém, no geral, de bolsas de estudos e/ou verbas decorrentes de projetos de pesquisa nas próprias universidades em que estudam.

14 cibercultura é um "neologismo que abrange os sistemas de técnicas, de práticas, de atitudes, de modos de pensamento e de valores, que se desenvolvem com o crescimento do ciberespaço. Este último sendo um novo meio de comunicação que surge da interconexão mundial dos computadores, incluindo a infra-estrutura material da comunicação digital, as informações on-line e os seres humanos que navegam e nutrem esse universo. (Castells, 1999). O termo ciberespaço foi cunhado por Gibson: (...) a consensual hallucination experienced daily by billions (...) a graphic representation of data abstracted from the banks of every computer in the human system. Unthinkable complexity. Lines of light ranged in the non space of the mind, clusters and constellations of data (GIBSON, 1984, p. 51).

15 Foram entrevistadas, até o momento (maio de 2006), trinta e nove mulheres que atuam com sistemas e redes computacionais nos contextos especificados nesse texto. 
Dentre as falas das entrevistadas, opto por algumas, explicitadas a seguir, a exemplo de Cátia Luciana ${ }^{16}$. Ela trabalha em projeto que integra extensa rede interna da universidade onde desenvolve sua pesquisa de mestrado ${ }^{17}$. O objetivo é a interligação do Centro de Engenharia Biomédica com o Instituto do Coração de São Paulo, para aquisição de banco de dados e transmissão de imagens no formato apropriado, que é o padrão conhecido como Daycom. Este permite o armazenamento de informações e dados de imagens do paciente, para inclusive poder ser emitido laudo a distância. Trabalha-se numa rede também em software genérico e livre, para poder disponibilizar essa tecnologia para a população em geral, além de direcionálas a hospitais, clínicas, médicos, etc. Para controle de equipamentos e respectiva transmissão de imagens é preciso informação segura. Portanto, as redes ${ }^{18}$ estão sendo montadas em sistemas tipo redes virtuais privadas chamadas virtual private networks (VPN), que são protocolos específicos de criptografia de dados e, também, se necessário, colocação de hardware específico para embaralhamento das informações e desembaralhamento no local, exigindo rapidez.

Ela assim se posicionou:

Trabalho na Escola Paulista de Medicina. Estou trabalhando em um projeto de implementação de uma rede física, de fios e cabos e softwares, para transmissão de imagens médicas. Sou coordenadora de integração de todo o projeto [o qual] envolve uma série de processos de imagens. No caso, compactação da imagem e transmissão com formato e protocolo definidos internacionalmente. A meta final é o diagnóstico por imagem, desde ultra-som, raio $X$, ressonância magnética, tomografia computadorizada, até angiografia, etc. (Cátia Luciana, 40 anos).

16 Os nomes explicitados neste texto foram trocados, embora nada há que possa desabonar as informantes caso sejam identificadas.

17 Ela estava em fase final da escrita de sua dissertação na época da entrevista: julho de 2003.

18 As informações sobre as redes computacionais foram prestadas a mim não só pelas entrevistadas, mas também por professores que orientam seus projetos de pesquisa. 
A informante ainda entende que "a mulher tem uma perspectiva mais geral das necessidades e consegue propor soluções mais facilmente do que os homens. Na parte de funções repetitivas o homem se destaca. Esta é a minha visão" (Cátia Luciana, 40 anos).

Para se ter uma sensação de que Cátia Luciana ${ }^{19}$ é real e de "carne e osso" (MALINOWSKI, 1986), relato de modo sintético sua trajetória, na qual se mesclam os âmbitos pessoal e público - o que muitas vezes pode colocar os/as sujeitos da ação em momentos de "ambigüidade de sua posição [portanto] numa categoria anômala [às categorias] masculino/feminina" (CORREA A, 1995, pág. 109) - no que diz respeito às suas escolhas dentro do seu "campo de possibilidades" dado (VELHO, 1999).

Isto porque Cátia Luciana cursava Medicina quando nasceram seus dois filhos: "um no segundo ano e outro no terceiro; e mesmo assim, eu terminei o quarto [ano]; no quinto e no sexto teriam plantões, que eles chamam de internato. Daí ficou inviável de eu estar freqüentando a faculdade com os dois pequenininhos ainda, um amamentando”. A dimensão pessoal de Cátia Luciana ficou em segundo plano em sua escolha por interromper o curso de Medicina, visto que opta pelo social/coletivo no que se refere à esfera doméstica; portanto, o lar e a opção de ficar com o marido e os filhos, situação só diferenciada mais tarde, quando pôde fazer outra faculdade. Portanto, ela coloca em evidência o recorrente problema das mulheres que têm filhos, casadas ou não, e não têm como atendê-los adequadamente com opções de babás devidamente preparadas para a função, ou creches, ou outras opções familiares. Com as opções alternativas, ela poderia, simultaneamente, atender não apenas o lar, mas também sua profissão. Essa defasagem na idade de mulheres nas áreas da ciência e da tecnologia é evidenciada em estudos e estatísticas de pesquisadoras que recorrem ao banco de dados do $\mathrm{CNPq}^{20}$.

19 A entrevista foi feita em restaurante da capital de São Paulo, em agosto de 2003, momento em que coincidiu de ambas - pesquisada e pesquisadora - estarem em trânsito por essa cidade, visto que moram em cidades e Estados diferentes.

20 Esta situação de defasagem foi um dos temas debatidos no Encontro Nacional de Núcleos e Grupos de Pesquisa "Pensando Gênero e Ciências", promovido pela Secretaria Especial de Políticas para as Mulheres, Ministério da Ciência e Tecnologia e Ministério da Educação, ocorrido em Brasília, de 29 a 31 de março de 2006. 
Mais tarde, já com os filhos crescidos, volta a estudar, dessa vez, optando pelo curso Ciências da Computação, uma opção que, na época, considerou interessante, já que morava no interior de Minas Gerais, para onde havia se mudado. Seu mestrado ${ }^{21}$ contemplou, portanto, seus conhecimentos educacionais tanto da medicina quanto da computação. Ela diz: [Na Informática] vi coisas possíveis de serem implementadas e realizadas e de serem postas em soluções para o usuário mesmo. Então, essa parte me fascinou. E como a Informática é ligada hoje em dia a todas as áreas, e eu já tinha feito alguns anos de Medicina, eu vi a possibilidade de ligar as duas coisas.

Exponho, agora, sobre a entrevistada Anita $^{22}$, que é solteira, estudou em colégio particular pertencente a uma fundação alemã e, desde criança, "gostava de ficar consertando coisinhas quebradas, liquidificador, rádios e, depois, gostei da Engenharia da Reabilitação no campo da biomedicina”. Após cursar Engenharia de Computação - quando adorou estudar "Engenharia Clínica", ela inicialmente atuou como "trainee em duas empresas em áreas diferentes: Telecomunicações, na especificação de sistemas para controle de laboratório; e hidrelétrica”. Em seguida, através de sua pesquisa de mestrado, atua na primeira e principal rede virtual - a NOVEL - de certa universidade paulista, rede esta que gerencia sistema de ordens de serviço atendendo usuários das diversas áreas de saúde da universidade, a exemplo do Hospital das Clínicas, com cinco mil equipamentos, do Hospital do Centro de Apoio Integral à Saúde da Mulher (CAISM), com dois mil equipamentos, do gastrocentro, hemocentro, etc. No total, na área de Saúde da universidade existem aproximadamente dez mil equipamentos que são mantidos e gerenciados pela equipe técnica de engenheiros e técnicos do Centro de Engenharia Biomédica da universidade. Anita diz:

21 Ela defendeu a dissertação de mestrado sobre redes computacionais no Centro de Engenharia Biomédica, em universidade pública paulista, no final de 2003.

22 À época da entrevista, ocorrida em seu campo de atuação laboratorial, em universidade pública paulista, em agosto de 2003, ela era mestranda no Centro de Engenharia Biomédica, e trabalhava com redes de computação. 
Trabalho com sistema de gerenciamento de manutenção de equipamentos médicos direcionados para setores da engenharia biomédica, que deve reunir informaçôes dos equipamentos e das atuações de manutenção dos equipamentos não só dos hospitais dessa universidade, mas de toda a rede de hospitais do Estado Trabalho mais na especificação do sistema computacional, onde a gente "conversa e vê", no próprio departamento, o fluxo dos encaminhamentos dados: como um equipamento chega até o hospital ou o grupo de manutenção, qual ação é tomada sobre o equipamento, quais as opções, os caminhos que uma ordem de serviço de um equipamento passa, até que o equipamento esteja pronto de volta para o usuário no hospital. Também, as partes de suprimentos, de especificação para a compra de equipamentos, aquisição de peças, são agregados do conserto do equipamento em si, que é o foco principal do sistema. Então, existe não só o controle do histórico do equipamento, mas o acompanhamento da ordem de serviço e do grupo de manutenção, que é muito raro nos sistemas que a gente compra comercialmente (Anita, 24 anos).

Outra entrevistada é Nataskyka, solteira, designer e produtora de softwares de entretenimento no segmento de jogos computacionais ${ }^{23}$. Não obstante seja uma representante feminina a adentrar um espaço que detém a hegemonia masculina, que são os games, ela tem certa limitação ao desenvolver seu trabalho, visto que, por exemplo, na concepção dos personagens femininos, sob sua responsabilidade, ela os constrói após estar concluída a série de personagens masculinos, aos quais ela deve adequar suas concepções criativas. Ela diz:

Na verdade, essa criação foi baseada em alguns critérios que a gente tinha sobre como deveriam ser, com movimentos pré-estabelecidos, baseados nos personagens

23 A entrevista ocorreu em fevereiro de 2004, em seu local de trabalho, em empresa nascente de base tecnológica localizada no sul do País. Esta empresa, como todas as demais onde estive e entrevistei as mulheres especificadas, desenvolve projetos advindos e/ou nascidos no seio de universidades, sempre em parceria. 
masculinos previamente criados por outro integrante da equipe. Segui essas exigências e criei as personagens femininas e as animações, a exemplo de estudos de movimento, anatomia, comportamento, expressões; no caso da interface, estou estudando cores, ergonomia, interatividade. São elementos necessários para compor o site que vai pro jogo. Baseadas em coisas pré-definidas. Não fui eu quem defini. Eu apenas executei conforme me foi pedido. No momento, também estou fazendo a revisão da interface do jogo (Nataskyka, 21 anos).

Portanto, ela tem liberdade criativa parcial, visto que deveria compor personagens femininos a partir dos personagens masculinos, já criados. Não participou, portanto, da concepção total do jogo, a exemplo de personagens, situações, estratégias e ações. Também, ao produzir sua parte nos jogos, diz que "o público de jogos é, em sua predominância, masculino. Tem-se que pensar nesse aspecto. Apesar de que, quando se desenvolve personagem feminino, tenta-se adaptá-la tanto aos homens que gostam de jogar com as mulheres, quanto às mulheres que preferem personagem feminino, quanto também às várias mulheres que gostam de jogar com personagens masculinos. " A noção de diversidade está presente em seu pensar, embora ela reforce a predominância masculina enquanto público-alvo dos jogos.

Exponho a fala de Maria, noiva, que cursou o segundo grau técnico em Informática e, em seguida, Engenharia de Computação. Sempre gostou de programar e teve incentivos dos professores do curso. A maioria das disciplinas contemplava "muita matemática, muito cálculo avançado, até porque a gente lida com a parte de Telecomunicações”. Em seguida, Maria foi fazer especialização em redes porque queria se diferenciar do restante da turma. Ela diz: "Eu não queria ser programadora porque foi isso que a maioria da turma se tornou". Ela trabalha em laboratório de computação de instituição pública de ensino universitário localizada no Sul do País: 
Faço a página, cuido da rede e dou manutenção no laboratório do próprio programa de pós-graduação. Porque a gente acaba ficando também na Administração, já que ainda tem a página do programa e respectivos cursos e atividades. Tem que estar cuidando dos e-mails também, gerenciando tudo isso (Maria, 27 anos).

Em outra instituição educacional de grande porte, que além de hardwares produz também softwares educacionais dirigidos para o ensino primário, secundário e médio, localizada em Curitiba-PR, entrevisto Angélica Dutra. Ela é casada, tem um casal de filhos, formou-se em Pedagogia e Psicologia, além de Informática. Foi uma das primeiras mulheres contratadas na área da Educação para conceber e produzir softwares educacionais dirigidos da $1^{\mathrm{a}}$ a $4^{\mathrm{a}}$ séries. Diz ter noção de que foi aceita, na época, por ter o perfil de pedagoga ("tida como continuadora da educação maternal"), além do perfil técnico em computação. Descobriu, após algum tempo na empresa que, embora tivesse curso superior como os demais homens que integravam a equipe, na época, além de capacidade e habilidade para trabalhar igualmente comparáveis às deles e compatíveis com o perfil exigido para a função, ganhava três a quatro vezes a menos do que os programadores homens e três vezes menos do que os desenhistas da equipe, que eram todos das áreas da Informática e de Desenho.

Angélica informa, ainda, sobre outra situação relacional de gênero ocorrida nessa instituição de ensino, onde é ressaltado o "cuidado extraordinário e meticuloso da mulher" no trabalho com produtos e artefatos de produtos. Ela diz que o setor exclusivo de programação geral, onde trabalha, é formado só por homens, com exceção de apenas duas mulheres (além dela) contratadas para fazerem os testes, ou seja, apenas testam para ver se os programas não contêm erros. Isto porque as mulheres seriam consideradas "mais atentas" do que os homens; é uma função que nada exige delas em termos de criatividade ou de concepção dos programas em si. Angélica, ainda uma vez, reforça este fato:

Na área da Programação, as mulheres foram contratadas, pelo menos no Departamento que eu trabalhava, sempre para 
fazerem testes. Depois que o software já está desenvolvido e pronto, é só fazer o teste; entrando no programa, teclando nos botôezinhos, clicando e vendo se tudo funciona. Quer dizer que não é uma atividade de produção. Você só vai testar. E supostamente a mulher presta mais atenção nos detalhes, etc. É bem direcionado (Angélica Dutra).

Em instituto de pesquisa na área tecnológica, localizado em universidade pública paulista, entrevistei $\mathrm{Márcia}^{24}$, formada em Física na Universidade de São Paulo (USP). Com isso, pôs por terra o "sonho da mãe" que era vê-la graduada em "Direito ou Letras". Ela é divorciada e tem um filho na pré-adolescência. Trabalha na Divisão de Informática e Telecomunicações, após estagiar no grupo de computação da Física. Atua com produção de softwares institucionais e, mais recentemente, educacionais, com redes de ensino estadual e municipal da capital paulista. Gosta muito do que faz, é docente em universidade particular nessa área de estudo e tem diversos estagiários sob sua responsabilidade. Enfatiza que quando faz pedidos para estágio, recebe propostas e currículos apenas de rapazes e não de moças ${ }^{25}$.

Poderia continuar a expor os depoimentos dessas mulheres. Porém, por limitação de espaço, entendo que as exposições feitas são suficientes para evidenciar o adentramento e a penetrabilidade das mulheres nos contextos laboratoriais/computacionais ora em foco.

\section{CONSIDERAÇÕES FINAIS}

Nesses contextos contemporâneos de trabalho, as mulheres, embora sua parcial visibilidade, dão vazão a expressões do ciberfeminismo, a partir da conceituação de Plant; não obstante, ressalto ainda uma vez, elas não

24 Márcia é mestra em Engenharia de Software pela USP. Especializou-se em Engenharia de Sistemas. Proferiu palestra (contando sua experiência profissional) no curso Ciência e Tecnologia: Têm Masculino e Feminino? ministrado na USP e montado por Regina Festa, representante da América Latina na Cátedra da Mulher na Unesco. A entrevista ocorreu em seu local de trabalho, em janeiro de 2004.

25 Este é um outro ponto que tenho explorado em minha tese de doutorado. 
têm preocupações em mente, nem com o movimento feminista e muito menos com o ciberfeminismo e respectivas militâncias. Todas as mulheres entrevistadas por mim durante a execução dessa pesquisa têm histórias específicas para contar sobre suas trajetórias pessoais na mescla com as trajetórias profissionais. Mas, têm em comum um diversificado leque de atividades vinculadas à área das Ciências Exatas e, mais especificamente com a Informática, as Engenharias e a Computação.

Porém, deixando a ingenuidade de lado, há que se reconhecer que ainda é tímida a entrada das mulheres nesses contextos tidos até então como hegemonicamente masculinos, tanto: em termos numéricos, quanto de desigualdades funcionais e salariais; quanto, ainda, da respectiva conscientização sobre assuntos relacionais de gênero, também por não ser, segundo elas próprias dizem, assunto de suas preocupações. Então, esse adentramento ainda está permeado de limitações, como a explicitada pela profissional que produz avatares femininos para jogos computacionais, ou daquelas contratadas para atuar no departamento de produção de softwares, mas que executam apenas testes em produtos já concebidos, produzidos e finalizados por homens; ou por estarem submetidas a condições salariais de inferioridade, embora tenham qualificações similares às de seus colegas de profissão.

Mesmo admitindo esse fosso nas conquistas - que devem ser mais abrangentes - a serem obtidas pelas mulheres, ainda assim, retomando a epígrafe desse texto, penso diferentemente de Rosi Braidotti. Isso porque não creio que as novas fronteiras, propiciadas pelas recentes tecnologias da informação e da comunicação direcionadoras a uma sociedade cada vez mais interligada por redes computacionais de trabalho e de lazer, colaborariam para alargar o distanciamento entre homens e mulheres no que respeita as situações igualitárias no viver pessoal e profissional. Tenho uma visão mais promissora e mais otimista do que Braidotti, tendo em vista as evidências de que as mulheres já iniciaram a ocupação desses espaços informacionais/ computacionais. A situação de rupturas ao status quo vigente já foi iniciada, em número mais significativo do que uma ou outra que, no passado recente, era caracterizada como a exceção que confirmava a regra. Talvez estejam faltando ações que impulsionem com mais rapidez e intensidade essas 
situações mais igualitárias, ações essas que podem ser mais incentivadas por políticas públicas que direcionem a uma maior conscientização (visando à formação de massa crítica) sobre as relações de gênero. Ações que devem ser feitas em cadeia, ininterruptas.

Ainda há muito a conquistar se as mulheres quiserem perseguir a igualdade de gênero, principalmente quando há entendimento de que mesmo que se tenha acesso a condições de igualdade, isto não é garantia de acesso a condições de identidade de gênero.

\section{REFERÊNCIAS}

BRAIDOTTI, Rosi. Cyberfeminism with a difference. Disponível em: http:// www.let.uu.nl/womens_studies/rosi/cyberfem.htm Acesso em: 11 maio 2004.

CASTELLS, Manuel. A sociedade em rede: A era da informação: economia, sociedade e cultura. Tradução de Roneide Venâncio Majer. São Paulo: Paz e Terra, 1999. v. 1.

CORREAA, Mariza. A natureza imaginária do gênero na história da antropologia. Cadernos Pagu.(5) 1995. p. 109-130.

GIBSON, William. Neuromancer. New York: Ace Books, 1984.

HARAWAY. Donna Jeanne. Modest_Witness@Second_Millennium. FemaleMan_Meets_OncoMouseTM: Feminism and Technoscience. New York: Routledge, 1997.

LEONEL, Vange. GameGrrrl. Anne-Marie Schleiner é a cyberfeminista que está revolucionando os jogos de computador. Mix Brasil. Disponível em: <http://www.mixbrasil.com.br > Acesso em: 20 ago 2004.

MALINOWSKI, Bronislaw. Malinowski. São Paulo: Ática, 1986. 
PLANT, Sadie. Mulher digital: O feminino e as novas tecnologias. Tradução de Ruy Jungmann. Rio de Janeiro: Record/Rosa dos Tempos, 1999.

STOFENMACHER, Ileana. Ciberfeminismo: La Feminización de la Red. Disponível em: <http://teknokultura.rrp.upredu/volumenes anteriores/Backup/rev_31_01_05/volumenes\%20anteriores/teknosphera/ ciberfeminismo/ciberfeminismo2. htm >Acesso em 31 jun 2005.

VELHO, Gilberto. Projeto, emoção e orientação em sociedades complexas. In: Individualismo e cultura: Notas para uma antropologia da sociedade contemporânea. Rio de Janeiro: Zahar, 1999. 
